\title{
Effects of Playing a Violent Video Game as Male Versus Female Avatar on Subsequent Aggression in Male and Female Players
}

\author{
Grace S. Yang ${ }^{1}$, L. Rowell Huesmann ${ }^{1}$, and Brad J. Bushman ${ }^{2 *}$ \\ ${ }^{1}$ University of Michigan, Ann Arbor, Michigan \\ ${ }^{2}$ The Ohio State University, Columbus, Ohio \\ ${ }^{3}$ VU University Amsterdam, the Netherlands
}

: : : : : : : : : : : : : : : : : : : : : : : : : : : : : : : : : :

Previous research has shown that violent video games can increase aggression in players immediately after they play. The present research examines the effects of one subtle cue within violent video games that might moderate these effects - whether the avatar is male or female. One common stereotype is that males are more aggressive than females. Thus, playing a violent video game as a male avatar, compared to a female avatar, should be more likely to prime aggressive thoughts and inclinations in players and lead to more aggressive behavior afterwards. Male and female university students $(N=242)$ were randomly assigned to play a violent video game as a male or female avatar. After gameplay, participants gave an ostensible partner who hated spicy food hot sauce to eat. The amount of hot sauce given was used to measure aggression. Consistent with priming theory, results showed that both male and female participants who played a violent game as a male avatar behaved more aggressively afterwards than those who played as female avatar. The priming effects of the male avatar were somewhat stronger for male participants than for female participants, suggesting that male participants identified more with the male avatar than did the female participants. These results are particularly noteworthy because they are consistent with another recent experiment showing that playing a violent game as an avatar with a different stereotypically aggressive attribute (black skin color) stimulates more aggression than playing as an avatar without the stereotypically aggressive attribute (Yang et al., 2014, Social Psychological and Personality Science). Aggr. Behav. 40:537-541, 2014. C 2014 Wiley Periodicals, Inc.

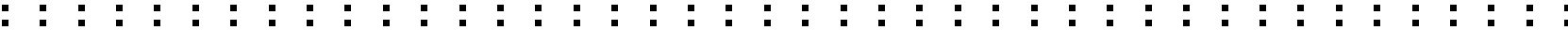

Keywords: violent video games; avatar sex; sexism; aggression

We sleep safe in our beds because rough men stand ready in the night to visit violence on those who would do us harm.

- George Orwell

We view ourselves on the eve of battle. We are nerved for the contest, and must conquer or perish... Be men, be free men, that your children may bless their father's name.

— Sam Houston

\section{INTRODUCTION}

Quotes like the ones above convey the stereotype that "real men" are rough, rugged, tough, aggressive, and violent. When someone says, "Be a man!" they often mean "toughen up" and be more "rough and ready" for whatever stands in your path. The media often reinforce this stereotype by depicting hyper-masculine men as prototypes of what it means to be a "real man." Particularly in video games, male characters are portrayed as being physically more aggressive and violent than female characters (Beasley \& Standely, 2002; Dietz, 1998). Even in magazine ads for video games, male characters are portrayed as more aggressive and violent than female characters (Dill \& Thill, 2007). The present research tests whether violent video games are more likely to increase aggression when players use male avatars than when they use female avatars.

\section{VIOLENT VIDEO GAME EFFECTS}

There is substantial evidence that playing a violent video game increases the aggression of the player shortly

Conflicts of interest: None.

${ }^{*}$ Correspondence to: Brad J. Bushman, School of Communication, The Ohio State University, 3127 Derby Hall, 154 North Oval Mall, Columbus, OH 43210-1339.E-mail: bushman.20@osu.edu

Received 22 August 2013; Revised 23 May 2014; Accepted 27 May 2014

DOI: $10.1002 / \mathrm{ab} .21551$

Published online 18 July 2014 in Wiley Online Library

(wileyonlinelibrary.com). 
afterwards (for meta-analytic reviews see Anderson et al., 2010; Greitemeyer \& Mügge, 2014). The most common explanation is that playing the game primes aggressive ideas and behavior. Neuroscientists and cognitive psychologists posit that the human mind acts as an associative network that consists of nodes and links. The nodes represent concepts, and the links represent associations among concepts. Exposure to a stimulus activates or prime concepts in memory (Fiske \& Taylor, 1984), even without the person being aware of it (e.g., Bargh \& Pietromonaco, 1982). The activation spreads along network links to associated concepts. Thus, playing a violent game increases the activation of concepts associated with aggression. In addition, thoughts are linked through spreading activation not only to other thoughts but also to emotional reactions and behavioral tendencies; so playing a violent game primes aggressive ideas, anger, and scripts for aggressive actions (Bushman \& Huesmann, 2006; Huesmann \& Kirwil, 2007). Consequently aggressive behavior becomes more likely. However, an understanding of this priming process raises some interesting questions about characteristics of a violent video game that could increase or decrease the priming effect. In particular, the current study investigates whether the effect of playing a violent game varies depending on the sex of the avatar played.

\section{AVATAR SEX AND VIOLENT VIDEO GAME EFFECTS}

Because of this common stereotype that men are aggressive and violent, there are theoretical reasons to believe that playing violent video games as a male avatar will increase aggression more than playing as a female avatar even if the avatars are identical in every respect except for their apparent sex. Because of the spreading activation process, characteristics of stereotypes connected with an avatar's sex should automatically activate associated constructs in memory. That is, the existing stereotypes about men as being characteristically more aggressive than women should be activated in a player's memory by playing a violent video game as a male avatar, and in turn this activation should increase the likelihood that the player will behave more aggressively afterwards because it primes ideas of behaving aggressively. Currently, however, empirical evidence showing the behavioral manifestations of media priming of sex stereotypes on aggression is lacking. The current research helps fill this gap by investigating the moderating role of avatar sex in the relation between violent game playing and aggressive behavior.

One theoretically plausible explanation is that the primary cause of behaving aggressively immediately after playing a violent game is that the violent game primes aggressive cognition and behavior. If this is the case, then playing a stereotypically more violent avatar (i.e., male rather than female avatar) and taking the perspective of an avatar of that sex would prime more aggression regardless of whether the player's sex is congruent with the avatar's sex. Based on this concept of dual priming from playing the violent game and from violent stereotype activation, we would expect that playing a male avatar rather than a female avatar would increase the propensity for both male and female players to behave aggressively afterwards. However, the effects might be larger for male players than for female players because male players should identify more with male avatars and thus be primed more by the aggression stereotypes associated with male avatars.

\section{METHODS}

\section{Participants}

Participants were 242 undergraduate students $(66 \%$ female; about $95 \%$ white) who received credit in exchange for their voluntary participation.

\section{Procedure}

After informed consent was obtained, participants were randomly assigned to play a violent game as either a male or female avatar for $15 \mathrm{~min}$. To increase the generalizability of findings (Wells \& Windschitl, 1999), participants played one of two violent games: (1) Street Fighter IV, or (2) Virtual Fighter 5. ${ }^{1}$ In both games, players engaged in one-on-one combat against a character of the same sex. All the game characters were White in order to prevent a potential confounding effect of race.

Next, participants completed what they thought was a different study on "food preferences" with an ostensible partner of the same sex. Both individuals indicated the foods they liked and disliked on a form, including spicy foods (e.g., hot sauce), and then exchanged forms with their "partner." The "partner" gave the spicy foods the lowest possible rating (i.e., $1=$ strongly dislike, on a 5-point scale). Through a rigged lottery, each person chose a food item for his or her partner to eat by selecting a piece of paper from a hat, and the participant always chose a paper that said "hot sauce." Each individual decided how much food the other would eat (including none at all), and they were told to eat all of it in order to provide an accurate evaluation of the food item. The amount of hot sauce the participant chose for the "partner" (in grams) was used to measure aggression

\footnotetext{
${ }^{1}$ There were no differences between the two fighting games, so they were combined for all analyses.
} 
(Lieberman, Solomon, Greenberg, \& McGregor, 1999). The hot sauce was extremely spicy. Even a very small amount burned and would be extremely unpleasant, especially for a person who strongly disliked spicy food. We also included several control variables (frequency of video game playing, competitiveness, identification with game avatars, etc.), but none of these covariates had significant effects and were therefore excluded from the analyses. A debriefing followed.

\section{RESULTS}

Data were analyzed using a 2 (avatar sex) $\times 2$ (participant sex) between-subjects ANOVA. Consistent with many other studies, male participant behaved more aggressively $(M=0.077, S D=0.083)$ than female participants $\quad(M=0.039, \quad S D=0.053), \quad F(1,235)=$ $20.18, p<.0001, d=0.59$. More important, as predicted, participants who played a violent video game as a male avatar behaved more aggressively afterwards $(M=0.086$, $S D=0.078)$ than those who played as a female avatar $(M=0.039, S D=0.047), F(1,235)=29.00, p<.0001$, $d=0.70$. Also, as expected, this suggested effect occurred separately in both male and female participants. As can be seen in Figure 1, both males and females who played a violent game as a male avatar behaved more aggressively afterwards than those who played as a female avatar, and the effects were significant separately for the male and female participants. $F(1,235)=19.68, p<.0001$,

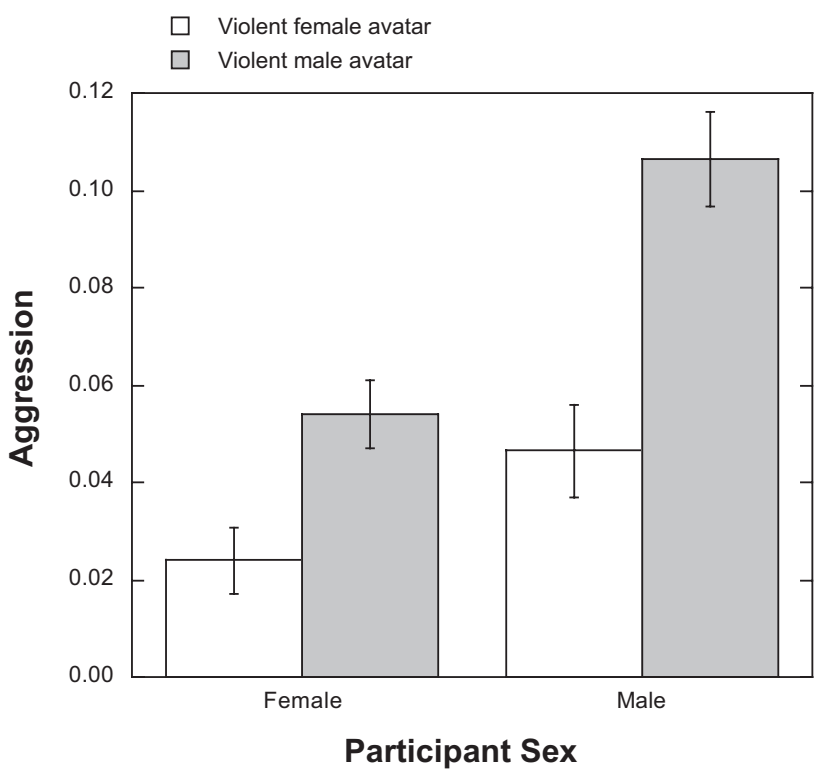

Fig. 1. Level of aggression for male and female participants who played a violent video game as a male or female avatar. Aggression is the amount of hot sauce (in grams) participants gave an ostensible partner who strongly disliked spicy food. Capped vertical bars denote 1 standard error. $d=0.58$ and $F(1,235)=9.31, \quad p<.0025, d=0.40$, respectively. There was also a nearly significant interaction between avatar sex and participant sex, $F(1,235)=3.21, p<.074, \eta^{2}=.013$. Figure 1 indicates that this interaction was due to male participants increasing their aggression $45 \%$ more than female participants did when they played a male avatar instead of a female avatar.

\section{DISCUSSION}

The present study showed that playing a video game as a violent male avatar increased aggression relative to playing as a violent female avatar for both men and women, as predicted by priming and perspective taking theory. These findings are particularly noteworthy because in most experiments, players of violent games are compared to players of nonviolent games. In this experiment, all participants played a violent game, but those who played as a male avatar behaved more aggressively afterwards than those who played as a female avatar. The observed effects tended to be stronger for men than women, but more importantly, the effects for females were separately significant. Both male and female participants who played a violent game as a male avatar behaved more aggressively afterwards than those who played the same game as a female avatar.

These results are consistent with the theory that playing a game as a particular avatar causes the participant to take the perspective of that avatar and to identify with the characteristics of that avatar, which primes stereotypes related to the characteristics of the avatar. Thus, both male and female participants have more aggressive scripts primed when playing as a male avatar than when playing as a female avatar.

Why was the effect of playing a male avatar compared with a female avatar $45 \%$ larger for males than for females? The male participants quite likely identified more with violent male avatars than the female participants did. There is empirical and theoretical support for this idea. Script theory (Huesmann, 1988, 1998), drawing on vicarious learning theory (Bandura, 1986), posits that identification with a violent media character increases the likelihood that aggressive scripts will be primed, retrieved, and used to guide behavior, and this has been empirically confirmed with longitudinal studies (Huesmann, Moise, Podolski, \& Eron, 2003). Our previous research also has suggested that the kind of wishful identification players have with avatars may have particularly strong effects, and that such wishful identification with violent video game characters amplifies the effect of violent games on aggression (Konijn, Nije Bijvank, \& Bushman, 2007).

It is also worth noting that the main results of this experiment and the priming explanation are consistent 
with another recent experiment that investigated the role of avatar race in violent games (Yang, Gibson, Lueke, Huesmann, \& Bushman, 2014). That study showed that playing a violent game as a black male avatar (instead of a white male avatar) primed more implicit attitudes about blacks being violent, which in turn stimulated more aggressive after the game was turned off. Thus, the current study is the second recent study showing that violent-game avatars with stereotypically aggressive attributes stimulate more aggression after gameplay than do avatars with less stereotypically aggressive attributes.

On the surface, the results of the current experiment may seem somewhat at odds with the results of another study that found that females who played a violent game had more aggressive thoughts afterwards when they played as a female avatar than when they played as a male avatar (Eastin, 2006). However, the differences in results are not surprising when one closely examines the experiments. First, that study used a first-person shooter game (in which the player has the same visual perspective as the avatar) with a mirror constantly showing the sex of the player's avatar to the player. This is likely to have boosted the identification of the female players with female avatars and to have diminished their identification with male avatars. Because of the greater identification with female avatars, the priming of aggressive thoughts in females from performing aggressive acts in the firstperson violent game should be somewhat stronger than in our third-person game (in which players observe the avatar from a more distant perspective). Similarly, because of the lesser identification with male avatars in the first-person game, the priming of aggressive thoughts in females from the male stereotypes associated with male avatars should be weaker than in our third-person game. This could contribute to the differences in results between the studies.

Second, unlike the current study in which the opponent's avatar's sex in the game was always matched with the player's avatar's sex, the other study (Eastin, 2006) varied the opponent's sex randomly. Consequently, the priming effect of the player's avatar's sex was combined with the priming effect of the opponent's avatar's sex to produce the total priming effect. In fact, that study found that the most aggressive thoughts occurred to a female player when her opponent's avatar was male and the least aggressive thoughts occurred to her when she and her opponent's avatar was female - a similar effect to what was found in our current study. Cognizant of the dual priming of player's and opponent's avatars, we did not include cross-sex conditions in our study. We believed that excluding potential confounding effects of mixed sexes for the two avatars would enable us to more clearly test our sex-stereotype priming theory, and it did.
Although the present study did not test directly the effects of violent games compared to non-violent games, many other studies have demonstrated the aggression priming effects of simply playing violent games (e.g., Anderson et al., 2010; Greitemeyer \& Mügge, 2014). This study's contribution is showing the additive priming effect of playing a violent game as a male avatar regardless of whether the player is a male or female. The most plausible explanation for these effects seems to be that playing a violent game as a male avatar more strongly primes aggression because of the stereotypic aggressive attributes associated with males.

Even though the current experiment only examines immediate effects of violent-game avatars on aggression, there are good reasons to believe that the repeated priming of aggressive thoughts or behavior from playing violent-male avatars may result in the incorporation of more aggressive scripts into the behavioral repertoire of the players, presumably outside their conscious awareness. Although basic priming effects are time limited, it has been hypothesized that frequent and repeated activation of scripts and thoughts can increase their chronic accessibility (Huesmann, 1988, 1998). Increased chronic accessibility of scripts leads to increased likelihood of utilizing scripts. Thus, the repeated priming of more aggressive thoughts and behavior from playing a violent game as a male avatar may contribute to making aggressive and stereotyped "scripts" more accessible, which can make players more susceptible to displaying long-term aggressive traits and behavioral tendencies. In turn, the continual activation and use of aggressive scripts learned and made accessible via frequent violent video game playing will increase the availability of other aggression-laden expectations and interpretations (Dodge \& Crick, 1990) as well as the likelihood of acquiring more aggressive scripts, leading to greater aggressive outcomes in the future. This is especially true considering the nature of repeated violent video game playing, which promotes new aggressive scripts being imitated and encoded particularly when their use in a game is successfully reinforced by various rewards (e.g., winning the game, gaining bonuses for killing and attacking).

In summary, violent video games that feature violent male characters should be of special concern. Because such games build on the stereotype that men are violent, they are likely to increase aggressive behavior in all players more than games featuring female or "un-gendered" avatars.

\section{REFERENCES}

Anderson, C. A., Shibuya, A., Ihori, N., Swing, E. L., Bushman, B. J., Sakamoto, A., ... Barlett, C. P. 2010. Violent video game effects on 
aggression, empathy, and prosocial behavior in Eastern and Western countries: A meta-analytic review. Psychological Bulletin, 136, 151-173. doi: 10.1037/a0018251

Bandura, A. 1986. Social foundations of thought and action. Englewood Cliffs, NJ: Prentice Hall.

Bargh, J. A., \& Pietromonaco, P. 1982. Automatic information processing and social perception: The influence of trait information presented outside of conscious awareness on impression formation. Journal of Personality and Social Psychology, 43, 437-449. doi: 10.1037/00223514.43.3.437

Beasley, B., \& Standely, T. C. 2002. Shirts vs. skins: Clothing as an indicator of gender role stereotyping in video games. Mass Communication \& Society, 5, 279-293. doi: 10.1207/ S15327825MCS0503_3

Bushman, B. J., \& Huesmann, L. R. 2006. Short-term and long-term effects of violent media on aggression in children and adults. Archives of Pediatrics \& Adolescent Medicine, 160, 348-352. doi: 10.1001/ archpedi.160.4.348

Dietz, T. L. 1998. An examination of violence and gender role portrayals in video games: Implications for gender socialization and aggressive behavior. Sex Roles, 38, 425-442. doi: 10.1080/13527260903448501

Dill, K. E., \& Thill, K. P. 2007. Video game characters and the socialization of gender roles: Young people's perceptions mirror sexist media depictions. Sex Roles, 57, 851-865. doi: 10.1007/s11199-007-9278-1

Dodge, K. A., \& Crick, N. R. 1990. Social information-processing bases of aggressive behavior in children. Personality and social psychology bulletin, 16(1), 8-22. doi: 10.1177/0146167290161002

Eastin, M. S. 2006. Video game violence and he female game player: Selfand opponent gender effects on presence and aggressive thoughts. Human Communication Research, 32, 351-372. doi: 10.1111/j.1468-2958

Fiske, S. T., \& Taylor, S. E. 1984. Social cognition. Reading, MA: Addison-Wesley.

Greitemeyer, T., \& Mügge, D. O. (2014). Video games do affect social outcomes: A meta-analytic review of the effects of violent and prosocial video game play. Personality and Social Psychology Bulletin, 40, $578-589$.

Huesmann, L. R. 1988. An information processing model for the development of aggression. Aggressive Behavior, 14, 13-24. doi: 10.1002/1098-2337(1988)14:1<13::aid-ab2480140104>3.0.co;2-j

Huesmann, L. R. 1998. The role of social information processing and cognitive schema in the acquisition and maintenance of habitual aggressive behavior. In R. G. Geen \& E. Donnerstein (Eds.), Human aggression: Theories, research, and implications for policy (pp. 73-109). New York: Academic Press.

Huesmann, L. R., \& Kirwil, L. 2007. Why observing violence increases the risk of violent behavior in the observer. In D. J. Flannery, A. T. Vazsonyi, \& I. D. Waldman (Eds.), The Cambridge Handbook of Violent Behavior and Aggression (pp. 545-570). Cambridge, UK: Cambridge University Press.

Huesmann, L. R., Moise, J., Podolski, C. P., \& Eron, L. D. 2003. Longitudinal relations between childhood exposure to media violence and adult aggression and violence: 1977-1992. Developmental Psychology, 39, 201-221. doi: 10.1037/0012-1649.39.2.201

Konijn, E. A., Nije Bijvank, M., \& Bushman, B. J. 2007. I wish I were a warrior: The role of wishful identification in the effects of violent video games on aggression in adolescent boys. Developmental Psychology, 43, 1038-1044. doi: 10.1037/0012-1649.43.4.1038

Lieberman, J. D., Solomon, S., Greenberg, J., \& McGregor, H. A. 1999. A hot new measure of aggression: Hot sauce allocation. Aggressive Behavior, 25, 331-348. doi: 10.1002/(sici)1098-2337(1999)25: $5<331$ ::aid-ab2 $>3.0$. co $; 2-1$

Wells, G. L., \& Windschitl, P. D. 1999. Stimulus sampling and social psychological experimentation. Personality and Social Psychology Bulletin, 25, 1115-1125. doi: 10.1177/01461672992512005.

Yang, G. S., Gibson, B., Lueke, A. K., Huesmann, L. R., \& Bushman, B. J. 2014. Effects of avatar race in violent video games on racial attitudes and aggression. Social Psychological and Personality Science, 5(6), 698-704. doi: 10.1177/1948550614528008. 